\title{
ELECTROANALYTICAL STUDY OF THE PESTICIDE ASULAM
}

\author{
HENRI P.A. NOUWS, CRISTINA DELERUE-MATOS, J OŚEL.F.C. LIMA, \\ E. MANUELA GARRIDO, PIETER VINCKE and NOEL A. MAES
}

\begin{abstract}
The electrochemical behaviour of the herbicide Asulam was studied by cyclic and square wave voltammetry. Asulam may be irreversibly oxidised at a glassy carbon electrode. Maximum currents were obtained at $\mathrm{pH}=1.9$ in aqueous electrolyte solution. Based on the electrochemical behaviour of Asulam, two analytical methodologies were developed for its determination in water samples, using square wave voltammetry (SWV) and flow injection analysis (FIA) coupled with an amperometric detector. Limits of detection of $7.1 \times 10^{-6} \mathrm{~mol} \mathrm{~L}^{-1}$ and $1.2 \times 10^{-8} \mathrm{~mol} \mathrm{~L}^{-1}$ for SWV and FIA respectively, were achieved. Repeatability was calculated by assessing the relative standard deviation (\%) for 10 consecutive determinations of one sample. The found values were $2.1 \%$ for SWV and $5.0 \%$ for FIA. Validation of the results provided by SWV and FIA methodologies was performed by comparison with results from an HPLC-DAD technique. Good relative deviations were found $(<5 \%)$. Recovery trials were performed to assess the accuracy of the results and the obtained values were between $84 \%$ and $107 \%$ for both methods.
\end{abstract}

Keywords: Asulam; Herbicides; Oxidation; Square wave voltammetry; Flow injection analysis; Amperometric detection

\section{INTRODUCTION}

Asulam, methyl sulphanylcarbamate, is a pesticide belonging to the carbamates family, which have seen increasing popularity due to their broad biological activity spectrum, as insecticides, herbicides, miticides, fungicides, nematocides or molluscicides. Asulam is a selective post-emergence herbicide controlling broadleaf plants, perennial grasses, and non-flowering plants. Plants readily absorb Asulam after emergence either by their roots, shoots, or leaves. It then interferes with the cell division and expansion processes of the plants ${ }^{[1]}$. Residues of Asulam in the soil may carry over through more than one growing season. Asulam dissolves poorly in water, but its sodium salt (the commercial form) dissolves very well in water. Asulam has the potential to contaminate ground water and is very mobile in sand, loamy soil, loam and clay loam soil. Both Asulam 
and its degradation products will leach through the soil. Due to its solubility in water and mobility in soil, Asulam could be transported into surface water bodies ${ }^{[2]}$. This justifies the importance of its control in residual waters and implies the search for precise, accurate, sensitive and selective analytical methodologies in order to perform a follow-up of Asulam levels in agricultural areas as well as in the general environment. It has also to be considered that in biodegradation studies it is necessary to use fast and in situ quantification methods for its determination.

The product or its residue analyses are mainly performed by HPLC with UV ${ }^{[3-11]}$, fluorimetric $^{[12-14]}$ or $\mathrm{DAD}^{[15]}$ detection. These methods imply an elaborate and timeconsuming sample preparation and analysis, being therefore unattractive for high frequency determinations. Other methods described for Asulam determination are $\mathrm{GC}^{[16]}$ and TLC ${ }^{[17,18]}$, but do not present any significant advantages over the HPLC methods.

In the present work, the electrochemical oxidation of Asulam at a glassy carbon electrode has been investigated using cyclic voltammetry (CV). The possible determination by square wave voltammetry (SWV) and by flow injection analysis (FIA) in combination with an amperometric detector is shown and the results compared to those of HPLC-DAD ${ }^{[19]}$ measurements. The proposed voltammetric method allows the interpretation of Asulam's oxidation process and the developed FIA methodology permits the drastic reduction of analysis time. Both methods were applied to the determination of Asulam in spiked natural water samples.

\section{EXPERIMENTAL}

\section{Apparatus}

All voltammetric measurements were performed using a computer controlled potentiostat Autolab PSTAT10 (EcoChemie), and a Metrohm 663 VA stand containing a three electrode cell with a glassy carbon working electrode (Metrohm 6.1204.000) (d=3.0 mm), an $\mathrm{Ag} / \mathrm{AgCl} / \mathrm{KCl} 3.00 \mathrm{~mol} \mathrm{~L}^{-1}$ reference electrode (Metrohm 6.0728.000), and a glassy carbon auxiliary electrode (Metrohm 6.1247.000). The system is controlled via PC 386 equipped with the General Purpose Electrochemical System (GPES) software package, version 3.0, from EcoChemie.

All flow-injection experiments were carried out using a 641 VA Metrohm detector linked to a $656 \mathrm{Metrohm}$ wall-jet cell containing a three-electrode system: a glassy carbon working electrode (Metrohm 6.0805.010) $(\mathrm{d}=3.0 \mathrm{~mm}$ ), an $\mathrm{Ag} / \mathrm{AgCl} / \mathrm{KCl}$ $3.00 \mathrm{~mol} \mathrm{~L}^{-1}$ reference electrode (Metrohm 6.0727.000), and a glassy carbon counter electrode (Metrohm 6.0805.010). The solutions were transported through the FIA system by a Gilson Minipuls 3 peristaltic pump, using pump tubing of the same brand. Samples and standards were introduced into the carrier stream through a six-port Rheodyne type 5020 injection valve. Omnifit Telfon tubes with an internal diameter of $0.5 \mathrm{~mm}$ connected by Gilson end-fittings and joints were used in the construction of the manifold. The confluence point was constructed as reported earlier ${ }^{[20]}$. The analytical signals were recorded on a Kipp \& Zonen BD 112 recorder.

The glassy carbon working electrodes were mechanically cleaned before each experiment by polishing its surface using a polishing kit (Metrohm 6.2802.010), first with $\alpha-\mathrm{Al}_{2} \mathrm{O}_{3}(0.3 \mu \mathrm{m})$ until a shining surface was obtained and after with only water. 
After polishing, the electrode was thoroughly washed with purified water and dried with tissue paper.

HPLC analyses were performed by a Beckman System Gold system, consisting of a 126 Solvent Module, a 508 Auto Sampler, and a 168 Detector $\left(\lambda_{\text {det }}=258 \mathrm{~nm}\right)$, controlled by a Beckman System Gold software program. The separation was carried out on a Lichocart Licrosphere $100 \mathrm{RP} 18$ column $(250 \times 4.6 \mathrm{~mm}, 5 \mu \mathrm{m}$ particle size $)$ at room temperature.

The $\mathrm{pH}$ measurements were done with a Metrohm 632-pH-meter with a combined glass electrode (Metrohm 6.0202.000).

\section{Reagents and solutions}

Asulam was obtained from Riedel-de-Haën-Pestanal. All other reagents were of Merck p.a. quality. Purified nitrogen 5 for voltammetric measurements was obtained from Linde, Sogás.

All solutions were prepared using purified water (conductivity $<0.1 \mu \mathrm{s} \mathrm{cm}^{-1}$ ) obtained from a Barnstead E-pure 4 system.

The electrolyte buffer solutions according to Britton-Robinson, ranging between $\mathrm{pH}$ 1.9 and $10.2^{[21]}$, were prepared by mixing different volumes of a phosphoric, acetic and boric acid stock solution (containing each acid component at $0.16 \mathrm{~mol} \mathrm{~L}^{-1}$ ) and a $0.8 \mathrm{~mol} \mathrm{~L}^{-1} \mathrm{NaOH}$ solution in order to obtain the required $\mathrm{pH}$. The ionic strength was adjusted with $1.34 \mathrm{~mol} \mathrm{~L}^{-1} \mathrm{KNO}_{3}$. Quantitative determinations were performed in $\mathrm{pH}=1.9\left(I=0.3 \mathrm{~mol} \mathrm{~L}^{-1}\right)$ Britton-Robinson buffer.

In the reference method, implying determinations by HPLC, separation was carried out using a mixture of $80 \%$ water and $20 \%$ acetonitrile (HPLC grade) as mobile phase which was filtered through a $0.45 \mu \mathrm{m}$ filter and degassed with helium.

\section{Standard and sample preparation}

Stock solutions of Asulam $\left(1.00 \times 10^{-3} \mathrm{~mol} \mathrm{~L}^{-1}\right)$ were prepared with an exact weight of the pure pesticide and diluted up to $50.00 \mathrm{~mL}$ with water. The standards used for the optimisation studies and calibration curves were prepared by dilution of these stock solutions with buffer solution (SWV) or with water (FIA and HPLC). Asulam concentrations between $1.0 \times 10^{-5}$ and $9.0 \times 10^{-5} \mathrm{~mol} \mathrm{~L}^{-1}$ were required for the calibrations. Natural water samples were collected from various locations in Porto (rivers and lakes) in polyethylene flasks. These samples were filtered and aliquots were taken, divided in three parts and spiked with Asulam. They were further diluted and directly analysed by the different methodologies using the calibration curve method.

\section{RESULTS AND DISCUSSION}

\section{Cyclic voltammetry}

The electrochemical behaviour of $1.0 \times 10^{-3} \mathrm{~mol} \mathrm{~L}^{-1}$ Asulam was studied in BrittonRobinson buffer solutions of $0.3 \mathrm{~mol} \mathrm{~L}^{-1}$ ionic strength over a wide $\mathrm{pH}$ range (1.9-10.2) at a glassy carbon electrode using cyclic and square wave voltammetry. 


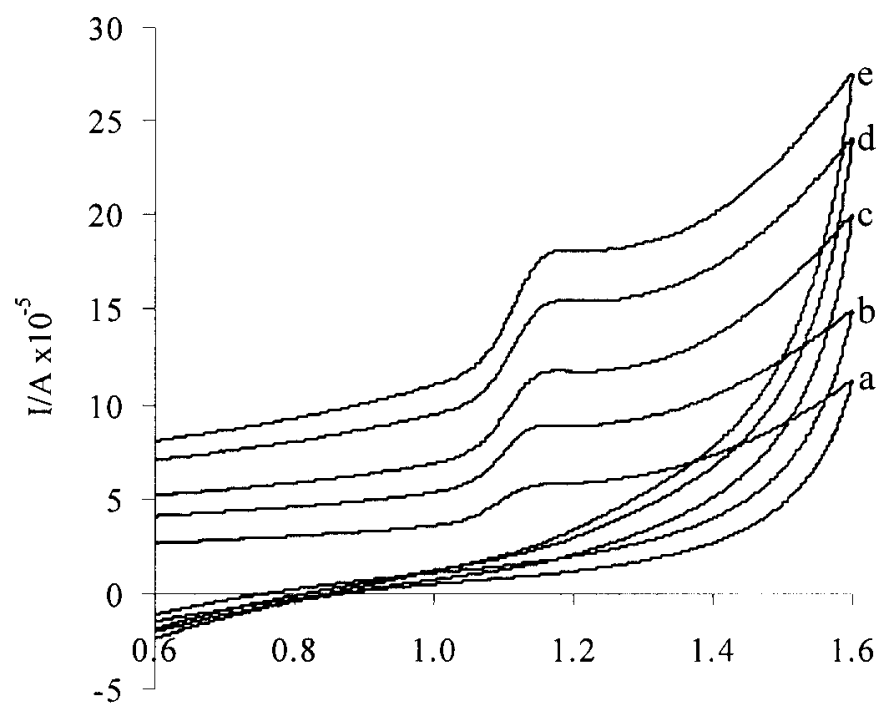

$\mathrm{E} / \mathrm{V}$

FIGURE 1 Cyclic voltammograms of a $1.00 \times 10^{-3} \mathrm{~mol} \mathrm{~L}^{-1}$ Asulam solution in a Britton-Robinson buffer pH 1.9. (a) 0.05 ; (b) 0.10 ; (c) 0.15 ; (d) 0.30 ; (e) $0.40 \mathrm{~V} / \mathrm{s}$.

Cyclic voltammograms showed that the oxidation of Asulam is an irreversible process over the scan rate range of $0.05 \mathrm{~V} \mathrm{~s}^{-1}$ to $0.40 \mathrm{~V} \mathrm{~s}^{-1}$ (see Fig. 1) with linear plots of peak currents $\left(I_{\mathrm{p}}\right)$ against square root of scan rate, proving that the reaction is diffusion controlled.

\section{Electrochemical behaviour of Asulam with pH}

The electrochemical behaviour of a $1.0 \times 10^{-3} \mathrm{~mol} \mathrm{~L}^{-1}$ Asulam solution with varying $\mathrm{pH}$ was studied using SWV. From the graphical representation of $E_{\mathrm{p}}$ vs. $\mathrm{pH}$ (see Fig. 2) it can be verified that for $\mathrm{pH}$ values lower than 7.4 the dependence of the peak potential corresponds to $39 \mathrm{mV}$ per unit of $\mathrm{pH}$, and for higher $\mathrm{pH}$ values the peak potential is independent of the $\mathrm{pH}$. It can be concluded that the oxidation process involves two electrons and one proton, meaning that it is likely that the reaction mechanism corresponds to an electron transfer followed by a chemical reaction, leading to irreversible product adsorption on the electrode surface. This is in agreement with the described mechanisms of anodic oxidation of carbamates ${ }^{[22]}$.

Regarding the relation $I_{\mathrm{p}}$ vs. $\mathrm{pH}$ (see Fig. 2) a maximum peak current intensity is obtained at a $\mathrm{pH}$ value of 1.9 , whereas higher $\mathrm{pH}$ values lead to a decrease in peak current intensity. Because the best peak definition was found at $\mathrm{pH} 1.9$, the BrittonRobinson electrolyte with this $\mathrm{pH}$ was selected for subsequent experiments.

\section{Analytical determination of Asulam using SWV}

The effects of frequency pulse amplitude and step potential were assessed with a $2.0 \times 10^{-4} \mathrm{~mol} \mathrm{~L}^{-1}$ Asulam solution, with the aim of optimising the experimental 


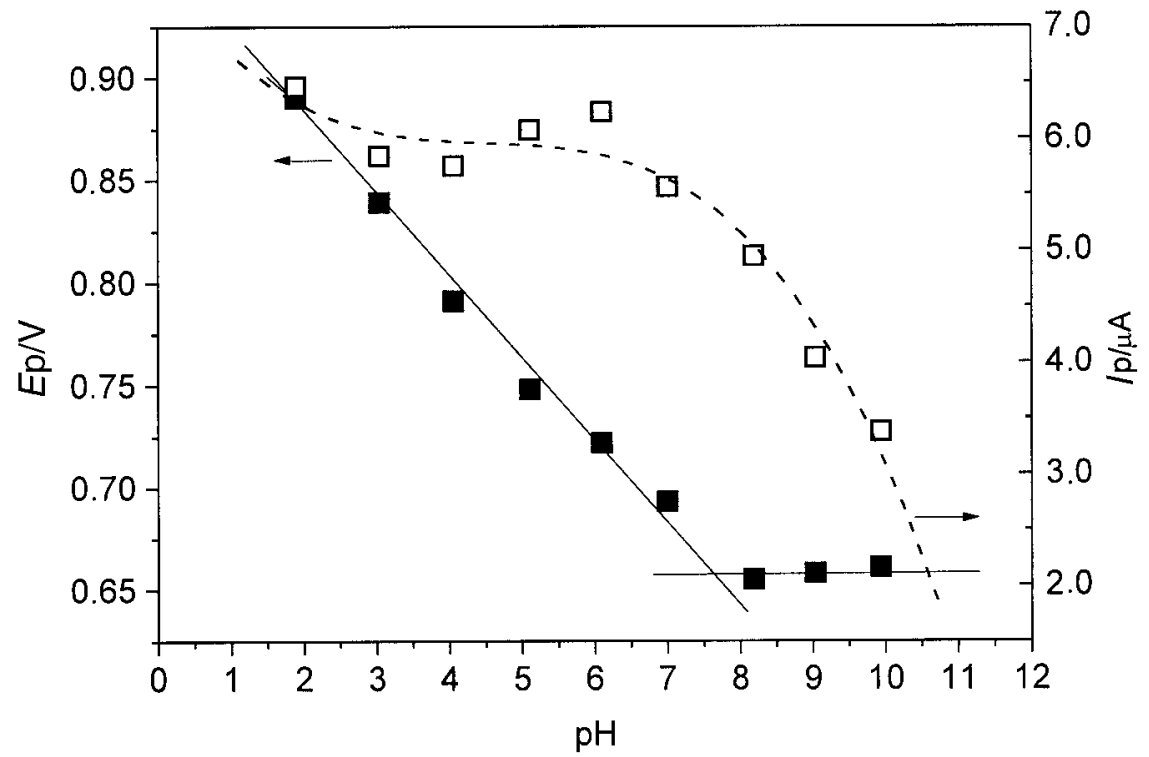

FIGURE 2 Plots of (-) $\mathrm{E}_{\mathrm{p}}$ and (-- - ) $\mathrm{I}_{\mathrm{p}}$ vs. pH from square wave voltammograms for $1.0 \times 10^{-3} \mathrm{~mol} \mathrm{~L}^{-1}$ Asulam in $\mathrm{pH}=1.9$ solutions. Frequency $50 \mathrm{~Hz}$; amplitude potential $50 \mathrm{mV}$ and step potential $2 \mathrm{mV}$.

conditions to use in square wave voltammetric determinations. The optimal parameters found were frequency $75 \mathrm{~Hz}$, pulse amplitude $50 \mathrm{mV}$ and step potential $2 \mathrm{mV}$.

Different voltammograms were recorded for Asulam concentrations ranging from $1.0 \times 10^{-5}$ to $9.0 \times 10^{-5} \mathrm{~mol} \mathrm{~L}^{-1}$ and the corresponding calibration curve outlined. The limit of detection ${ }^{[23]}$ was $7.1 \times 10^{-6} \mathrm{~mol} \mathrm{~L}^{-1}$. The repeatability was assessed by calculating the relative standard deviation, obtaining $2.1 \%(n=10)$ for a $5.00 \times$ $10^{-5} \mathrm{~mol} \mathrm{~L}^{-1}$ Asulam concentration.

\section{Flow injection analysis with amperometric detection}

A schematic representation of the FIA manifold for the determination of Asulam in water samples is shown in Fig. 3. The system was developed optimising each parameter separately and considering the best compromise between sensitivity, reproducibility, sampling rate and low consumption of reagents.

The sample was injected into the ultra-pure water carrier stream and transported to the confluence point where the carrier stream was mixed with a Britton-Robinson buffer of $\mathrm{pH} 1.5$, to result in a mixture with $\mathrm{pH} 1.9$ in the amperometric cell.

Based on the results of the voltammetric study the electrode potential was optimised between $+1.00 \mathrm{~V}$ and $+1.30 \mathrm{~V}$ vs. $\mathrm{Ag} / \mathrm{AgCl}$, by $50 \mathrm{mV}$ steps, finding an optimum at $+1.20 \mathrm{~V}$ vs. $\mathrm{Ag} / \mathrm{AgCl}$.

The optimum flow rate was found to be $2.4 \mathrm{ml} / \mathrm{min}$ (flow $\mathrm{C}=$ flow $E=1.2 \mathrm{~mL} / \mathrm{min}$ ), no higher flow rates were tried, because this would exceed the maximum flow allowed in the wall-jet cell ${ }^{[24]}$.

With the purpose of selecting the most adequate injection volume, loops with lengths enabling the insertion of volumes between 35 and $325 \mu \mathrm{L}$ were prepared for the injection valve. These real volumes (including the internal volume of the injection valve) 


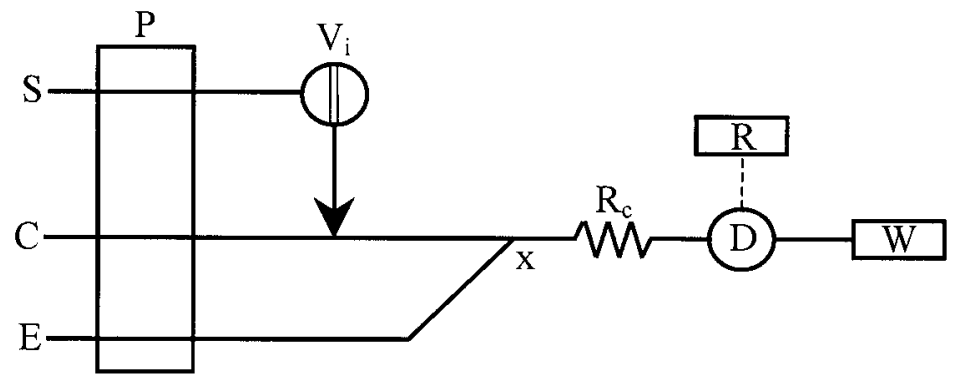

FIGURE 3 Flow injection manifold for the determination of Asulam in water samples: P, peristaltic pump; $\mathrm{V}_{\mathrm{i}}$, injection valve; $\mathrm{S}$, sample; $\mathrm{C}$, carrier stream; $\mathrm{E}$, electrolyte solution; $\mathrm{x}$, confluence point; $\mathrm{R}_{\mathrm{c}}$, reactor; $\mathrm{D}$, amperometric detector; $\mathrm{R}$, recorder; $\mathrm{W}$, waste.

were determined by titration of the volume obtained from 10 replicate injections of a solution of known concentration ${ }^{[25]}$. A loop with an injection volume of $180 \mu \mathrm{L}$ was selected because of the highest linear sensitivity attained.

Several reactor lengths were tried and a length of $110 \mathrm{~cm}$ was selected, whereas smaller reactors were ineffective for the perfect mixture of the carrier stream with the buffer solution and longer reactors caused a decrease of sensitivity and sampling rate.

Using the optimised parameters, a linear calibration curve between $1.0 \times 10^{-5}$ mol L ${ }^{-1}$ and $9.0 \times 10^{-5} \mathrm{~mol} \mathrm{~L}^{-1}$ Asulam was obtained. With this system the limit of detection was $1.2 \times 10^{-8} \mathrm{~mol} \mathrm{~L}^{-1[23]}$. The repeatability of the FIA method was assessed by calculating the relative standard deviation for 10 consecutive injections of a $5.0 \times 10^{-5} \mathrm{~mol} \mathrm{~L}^{-1}$ Asulam solution. The result obtained was less than $5.0 \%$. Using the developed FIA manifold about 120 injections per hour could be achieved.

\section{Comparison between the developed methods and a reference method}

The determination of Asulam in 5 different types of spiked waters $\left(c=2.0 \times 10^{-3}\right.$ mol $\mathrm{L}^{-1}$ ) was obtained by both methods. The mean values obtained by SWV and FIA were compared with those obtained by an HPLC method and showed relative deviations (RD) of less than $9.8 \%$ (see Table I).

Five different spiked water samples containing $5.0 \times 10^{-5} \mathrm{~mol} \mathrm{~L}^{-1}$ Asulam were analysed in triplicate by both methods, in order to assess the recovery. The obtained recovery values are shown in Table II.

TABLE I Determinations of Asulam in different spiked environmental water samples, using SWV, FIA and on HPLC-DAD reference method and the corresponding relative deviations*

\begin{tabular}{|c|c|c|c|c|c|}
\hline \multirow[t]{2}{*}{ Sample } & \multirow{2}{*}{$\begin{array}{c}S W V \\
\text { conc. } \\
\left(\times 10^{-3} \mathrm{~mol} \mathrm{~L}^{-1}\right)\end{array}$} & \multirow{2}{*}{$\begin{array}{c}\text { FIA } \\
\text { conc. } \\
\left(\times 10^{-3} \mathrm{~mol} \mathrm{~L}^{-1}\right)\end{array}$} & \multicolumn{3}{|c|}{$H P L C-D A D$} \\
\hline & & & $\begin{array}{c}\text { conc. } \\
\left(\times 10^{-3} \mathrm{~mol} \mathrm{~L}^{-1}\right)\end{array}$ & $\begin{array}{c}R D(\%) \\
S W V\end{array}$ & $\begin{array}{c}R D(\%) \\
F I A\end{array}$ \\
\hline 1 & $1.97 \pm 0.02$ & $1.93 \pm 0.04$ & $1.97 \pm 0.01$ & +0.0 & -2.0 \\
\hline 2 & $1.74 \pm 0.08$ & $1.90 \pm 0.05$ & $1.93 \pm 0.02$ & -9.8 & -1.6 \\
\hline 3 & $1.93 \pm 0.11$ & $1.91 \pm 0.03$ & $1.97 \pm 0.01$ & -2.0 & -3.1 \\
\hline 4 & $1.98 \pm 0.12$ & $2.02 \pm 0.04$ & $1.96 \pm 0.01$ & +1.0 & +3.1 \\
\hline 5 & $1.95 \pm 0.05$ & $2.02 \pm 0.04$ & $1.96 \pm 0.02$ & -0.5 & +3.1 \\
\hline
\end{tabular}

* Mean and standard deviation of three determinations. 


\section{ELECTROANALYTICAL STUDY}

TABLE II Results of the recovery studies for SWV and FIA for the determination of Asulam in spiked water samples

\begin{tabular}{lcr}
\hline Sample & Recovery $(\%)$ & Recovery $(\%)$ \\
& SWV & \multicolumn{1}{c}{ FIA } \\
\hline 1 & $99.6 \pm 1.8$ & $84.2 \pm 0.8$ \\
2 & $99.3 \pm 3.0$ & $101.0 \pm 7.1$ \\
3 & $97.3 \pm 1.6$ & $98.6 \pm 4.2$ \\
4 & $100.2 \pm 3.2$ & $107.0 \pm 6.8$ \\
5 & $98.7 \pm 5.3$ & $100.1 \pm 7.6$ \\
\hline
\end{tabular}

\section{CONCLUSIONS}

Based on the electrochemical behaviour of Asulam, two analytical methodologies were developed using SWV and FIA with amperometric detection at $+1.20 \mathrm{~V}$ vs. $\mathrm{Ag} / \mathrm{AgCl}$, to quantify the herbicide in spiked natural water samples. Both developed methods are good alternatives to the comparative HPLC method, since they are simple, less expensive, show results that are in good agreement with those obtained with the comparative method, and in FIA the sampling rate is much higher. Both developed electrochemical methods can be used to study the biodegradation processes of Asulam.

Moreover, the use of solid electrodes has the advantage of making the quantification in situ possible, allowing biodegradation control to proceed in a simpler and more efficient way.

\section{Acknowledgements}

Fundação para a Ciência e Tecnologia (FCT) is thanked for financial support through project POCT1/35287/AGR/2000, and the Socrates/Erasmus program (Pieter Vincke).

\section{References}

[1] CDS Tomlin (Ed.), The Pesticide Manual, 11th Edn., pp. 53-55. British Crop Protection Council (1997).

[2] Infoventures, Asulam (1999). [www http://www.infoventures.com]

[3] J.F. Lawrence, J.G. Panopio and H.A. McLeod, J. Agric. Food. Chem., 28, 1323-1325 (1980).

[4] R.T. Kon, L. Geissel and R.A. Leavitt, Food Addit. Contam., 1, 67-71 (1984).

[5] D. Kaniansky, V. Madajova and M. Hutta, J. Chromatogr., 286, 395-406 (1984).

[6] A. Yamamoto, M. Ohto and S. Hosorogi, Jpn. J. Toxicol. Environ. Health, 38, 374-377 (1992).

[7] H. Ohno and T. Aoyama, Jpn. J. Toxicol. Environ. Health, 38, 202-208 (1992).

[8] Y.P. Pan, T.G. Hiroo and C.L. Chen, Sepu, 11, 302-303 (1993).

[9] T. Suzuki, K. Yaguchi and I. Kano, J. Chromatogr., 643, 173-179 (1993).

[10] M.C. Gennaro, C. Abrigo and D. Giacosa, J. Chromatogr. A, 718, 81-88 (1995).

[11] H. Uemori, K. Yoshida and M. Fukumoto, Bunseki-Kagaku, 44, 443-447 (1995).

[12] J. Lochtman, T. Gernikeitis and R. Hueskes, Gewaesserschutz, -Wasser, -Abwasser, 125, 576-578 (1991).

[13] F. Garcia-Sanchez, A. Navas-Diaz and A. Garcia-Pareja, J. Chromatogr. A., 678, 347-354 (1994).

[14] F. Garcia-Sanchez, A. Navas-Diaz and A. Garcia-Pareja, J. Liq. Relat. Technol., 20, 603-615 (1997).

[15] H. Mori, T. Sato and H. Nagase, Jpn. J. Toxicol. Environ. Health, 44, 182-194 (1998).

[16] H. Tsuji, N. Henmi and Y. Kaneda, Jpn. J. Toxicol. Environ. Health, 41, 292-299 (1995).

[17] M. Kurucova and J. Kovac, Agrochemia, 23, 49-51 (1983).

[18] A.E. Smith and L.J. Milward, J. Chromatogr., 265, 378-381 (1983).

[19] Riedel-de Haën, Certificate of Analysis Asulam (2000).

[20] S. Alegret, J. Alonoso, J. Bartroli, A.A.S.C. Machado, J.L.F.C. Lima and J.M. Paulis, Quím. Anal., 6, 278-292 (1987). 
[21] C.M. Fernandez and V.C. Marti, Talanta, 24, 747-748n (1977).

[22] M.H. Baizer and H. Lund, Organic Electrochemistry. 2nd Edn., Marcel Dekker Inc., New York (1983).

[23] J.N. Miller, Analyst, 116, 3 (1991).

[24] Metrohm AG CH-9100 Herisau, Electrochemical detection in HPLC (1984).

[25] J.L.F.C. Lima and A.O.S.S. Rangel, J. Int. Sciences de la Vigne et du Vin, 24, 49-61 (1990). 